\title{
Introduction
}

\author{
Maxine L Stitzer
}

I am currently professor of behavioural biology in the Department of Psychiatry and Behavioral Sciences, Johns Hopkins University School of Medicine. My research has examined both pharmacological and behavioural treatment of drug abuse, and specifically their combination for the treatment of tobacco dependence. I am pleased to be both a presenter and a moderator this morning.

Our other presenter, who will follow the panel discussion, is Mike Synar. Mr Synar served in the US House of Representatives from 1978-94, representing Oklahoma's second district. During his tenure, he was known for his willingness to pursue his convictions, even if that meant bucking established interests, particularly the tobacco industry. $\mathrm{Mr}$ Synar achieved passage of the Synar Amendment which links success at controlling youth access to tobacco at the state level with the receipt of federal aid dollars. We are really pleased to have you here to share your insights about policy initiatives and political reality.

Our first panelist is Michael C Fiore. He is director of the Center for Tobacco Research and Intervention, as well as an associate professor in the Department of Medicine at the

Behavioral Research Unit, Johns Hopkins University, Baltimore, Maryland USA

M L Stitzer
University of Wisconsin Medical School. Dr Fiore worked as a medical epidemiologist at the Office on Smoking and Health, and he has published extensively on nicotine, and nicotine replacement as a smoking cessation aid. $\mathrm{He}$ is also currently chair of the clinical guidelines panel on smoking prevention and cessation for the Agency for Health Care Policy and Research.

Ellen R Gritz is professor and chair of the Department of Behavioral Science at the University of Texas MD Anderson Cancer Center where she holds the Annie Laurie Howard research professorship. She has published extensively on cigarette smoking behaviour and is an expert on cessation issues in special populations including women, adolescents, ethnic minorities, and medical populations. Dr Gritz was also the first recipient of the Joseph W Cullen Memorial Award from the American Society of Preventive Oncology.

Finally, we have our third panelist. Michael Pertschuk is co-director of the Advocacy Institute, a non-profit organisation "dedicated to strengthening the advocacy capacity of the least powerful citizen groups and communities so that their voices will be heard and heeded." From 1965 to 1977 , in various capacities, $\mathrm{Mr}$ Pertschuk worked for the Senate Commerce Committee. Here, he helped guide landmark consumer legislation, including the broadcast ban on cigarette advertising. He served as chairman of the Federal Trade Commission from 1977 to 1984, and we are really fortunate to have him here today.

\section{Policy initiatives to enhance smoking cessation and harm reduction}

\author{
Maxine L Stitzer
}

The overall goal of the conference reported in this supplement is to consider new strategies and interventions expected to lower the harm to society that result from tobacco smoking. In general, there are two ways to achieve a harm reduction goal. The first is to reduce the prevalence of smoking by using interventions that reduce smoking initiation, promote attempts to stop smoking, and increase the success of these attempts once initiated. A second approach to harm reduction is to limit exposure to the most harmful substances or behaviours related to an addiction, while conceding that the addiction itself will continue in some form.

Harm reduction has received serious consideration and discussion as a strategy for dealing with hard drug abuse, where limiting the risk of exposure to HIV infection is an important concern. The concept of harm reduction has had a more limited application to tobacco dependence; thus its consideration represents a novel contribution of the present meeting. Harm reduction to continuing smokers might be accomplished by changing the nature of the cigarettes so that fewer 